\title{
Epidemiological Characteristics and Survival Analysis of Patients With Nasopharyngeal Cancer in Western Greece
}

\author{
Christos S. Avdulla ${ }^{1}$, Theodoros Papadas ${ }^{2}$, Nicholas Mastronikolis ${ }^{2}$, Eleni Jelastopulu ${ }^{1}$ \\ 1. Department of Public Health, University of Patras, Patras, GRC 2. Department of Otorhinolaryngology, University of \\ Patras, Patras, GRC
}

Corresponding author: Eleni Jelastopulu, jelasto@upatras.gr

\section{Abstract \\ Purpose}

The purpose of this study is to assess the overall survival (OS) of patients with nasopharyngeal cancer and the factors affecting the survival rates.

\section{Methods}

A retrospective cohort study was performed, including 77 patients with nasopharyngeal cancer diagnosed and treated in the Otorhinolaryngology Clinic of the University Hospital of Patras during 1990-2017. The prognostic impact of age, gender, occupation, smoking/alcohol, and TNM staging were evaluated using Kaplan-Meier analysis.

\section{Results}

During the last 28 years, nasopharyngeal cancer (NPC) was higher in men ( $80.5 \%$ of patients) than women (19.5\%) (mean age 56-years). Most patients were smokers (64.9\%, mean 70 pack-years) and 35 (45.5\%) of them were alcohol users. Postoperative staging indicated 39\% stage-III, 26\% stage-IV, and $26 \%$ stage-I. Histologically, $70.1 \%$ of the volumes were WHO-III, $20.8 \%$ WHO-II, and $5.2 \%$ WHO-I. Also, $98.7 \%$ of patients received radiotherapy, $85.7 \%$ chemotherapy, and $20.8 \%$ surgery. More than half were farmers (26\%), self-employed (16.9\%), and workers (14.3). During the follow-up (mean 66 months), 38 (49.5\%) patients died, $88.9 \%$ from disease-related causes. The 5 -year survival was $58.8 \%, 74.5 \%$ for non-smokers, and $49.1 \%$ for smokers, and 10 -year survival was $43.6 \%, 63.4 \%$, and $31.6 \%$, respectively $(\mathrm{p}=0.016)$. Moreover, significant statistical differences were observed in age $(\mathrm{p}=0.054)$, time period of diagnosis and treatment $(\mathrm{p}=0.002)$, cause of death $(\mathrm{p}=0.033)$, and metastatic disease $(\mathrm{p}=0.023)$.

\section{Conclusions}

Review began 03/16/2021 Review ended 04/19/2021 Published 04/27/2021

\section{Copyright 2021}

Avdulla et al. This is an open access article distributed under the terms of the Creative Commons Attribution License CC-BY 4.0., which permits unrestricted use, distribution, and reproduction in any medium, provided the original author and source are credited.
Age, stage in disease detection, tumor characteristics, treatment, and tobacco abuse are important factors that affect the OS of patients with NPC during the three last decades.

Categories: Otolaryngology, Oncology, Epidemiology/Public Health

Keywords: nasopharyngeal cancer, cohort study, survival analysis, prognostic factors, western greece, tnm staging

\section{Introduction}

Nasopharyngeal carcinoma (NPC) is a relatively rare neoplasm representing $0.8 \%(1.1 \%$ in males and $0.4 \%$ in females) of all human neoplasia worldwide [1]. According to global statistics on cancer, in 2018, there were over 129,079 cases of NPC [1]. In addition, one of the peculiarities of this neoplasm is its geographical distribution in the countries of Southeast Asia and the Mediterranean, and consequently, in Greece $[1,2]$.

Nasopharyngeal carcinoma can occur at any age, but the majority of cases are diagnosed in adults between the third and fifth decades. Moreover, symptoms of NPC vary and are atypical in the early stages of the disease, leading to a delay in diagnosis. As a matter of fact, the NPC appears to be associated with smoking, alcohol, dietary, professional, and genetic factors, and histological subtypes that are directly related to the Epstein-Barr virus infection $[1,3]$.

The selected treatment of NPC depends on various factors, and a combination of chemotherapy and radiotherapy is mostly performed, while lymphatic cleansing of the cervix occurs only when the disease is present or relapsed after the initial course of therapy [3]. Furthermore, response to treatment is much more relevant to the histological type of cancer and the presence of distant metastases and less to the extent of topographical disease. Interestingly, the prognosis of the disease in the early stages is very good, while in the most advanced stages, the 5-year survival is limited to 50-70\%, remaining higher than many other 
The aim of this study is to assess the survival (5-year and 10-year) of patients with NPC, the trends of survival during the three last decades, and the factors affecting the survival rates in the University Hospital of Patras, Western Greece.

\section{Materials And Methods \\ Patients}

A retrospective study of a series of patients was carried out which included all patients with cancer diagnosed and treated at the University Hospital of Patras, Western Greece. In the period 1990-2017, 77 patients (55 men and 22 women) were diagnosed with nasopharyngeal cancer. Prognostic factors such as gender, age, occupation, tobacco/alcohol, histology, and staging were assessed using the SPSS (IBM Corp, Armonk, NY, USA) and Kaplan-Meier method.

All patients' data were evaluated for 5-year and 10-year survival rates. The tumors were staged using the 1997 AJCC (American Joint Committee on Cancer) and UICC (Union Internationale Contre le Cancer) criteria. This system takes into account the size of the tumor (T), the number, size, and location of the cervical lymph nodes $(\mathrm{N})$, and the presence or absence of distant metastases $(\mathrm{M})$. Also, at the histological level, the classification for nasopharynx cancer is proposed by the World Health Organization (WHO) and subdivided into three categories.

\section{Ethics}

The survey complied with all ethical standards for research. Prior to its inception at the otorhinolaryngology clinic, permission was obtained from the Scientific Council of the University General Hospital of Patras.

\section{Statistical analysis}

The collected data were analyzed with the SPSS statistical version v.25 (IBM Corp, Armonk, NY, USA). Data are presented as mean value, standard deviation, range, and percentages. Survival analysis was performed using the Kaplan-Meier method and the comparison between the two survival curves was performed using the log-rank test. The Kaplan-Meier method was selected due to the greater accuracy of the results for small groups and censored data and was used for procuring the 5-year and 10-year survival percentages and graphs. The final point considered in our analysis was overall survival (OS). Time was calculated from the date of diagnosis to the event of interest, which was death due to any cause. Results are considered statistically significant when the p-value is less than or equal to 0.05 .

\section{Results}

\section{Demographic results}

In the last 28 years, a higher frequency of nasopharyngeal carcinoma (NPC) was observed in males (80.5\%) than in females (19.5\%) (Table 1). The mean age of the disease was 56 years (range 16-85 years). Most patients were smokers (64.9\%) with an average of 70 pack-years (range 0-200 pack-years) and 35 (45.5\%) were alcohol users. Specifically, 16.9\% light drinkers (they drank less than 1 day per week), 14.3\% moderate drinkers (they drank 1 to 3 drinks per day or more times per week), and 14.3\% heavy drinker (they drank more than 3 glasses per day). More than $50 \%$ of the patients were farmers (26\%), self-employed (16.9\%), or workers (14.3\%). 


\section{Cureus}

\begin{tabular}{|c|c|c|}
\hline Characteristic & $\mathbf{n}$ & $\%$ \\
\hline \multicolumn{3}{|l|}{ Gender } \\
\hline Male & 62 & 80.5 \\
\hline Female & 15 & 19.5 \\
\hline Total & 77 & 100 \\
\hline \multicolumn{3}{|l|}{ Smokers } \\
\hline Yes & 50 & 64.9 \\
\hline No & 26 & 33.8 \\
\hline Total & 76 & 98.7 \\
\hline \multicolumn{3}{|l|}{ Alcohol use } \\
\hline None & 40 & 51.9 \\
\hline Low & 13 & 16.9 \\
\hline Medium & 11 & 14.3 \\
\hline High & 11 & 14,3 \\
\hline Total & 75 & 97.4 \\
\hline \multicolumn{3}{|l|}{ Occupation } \\
\hline Farmers & 20 & 26 \\
\hline Builders & 9 & 11.7 \\
\hline Self- employed & 13 & 16.9 \\
\hline Professional drivers and mechanics & 6 & 7.8 \\
\hline Workers & 11 & 14.3 \\
\hline Others & 16 & 20.8 \\
\hline Total & 75 & 97.4 \\
\hline
\end{tabular}

\section{TABLE 1: Characteristics of the study population}

After diagnosis, 98.7\% of the patients received radiotherapy, 85.7\% received chemotherapy, while only 16 (20.8\%) patients underwent surgery (Table 2). During the observation period, 38 (49.5\%) patients died, out of them, $68.4 \%$ due to metastatic or generalized carcinomatosis, $18.4 \%$ of relapse, and $13.1 \%$ of other causes unrelated to the disease. Only three patients (3.9\%) had a family history of NPC. 


\section{Cureus}

\begin{tabular}{|c|c|c|}
\hline Characteristic & $\mathbf{n}$ & $\%$ \\
\hline \multicolumn{3}{|l|}{ Treatment } \\
\hline Radio and Chemotherapy & 66 & 85.7 \\
\hline Radiotherapy & 10 & 13 \\
\hline Total & 76 & 98.7 \\
\hline \multicolumn{3}{|l|}{ Surgical treatment } \\
\hline Yes & 16 & 20.8 \\
\hline No & 60 & 77.9 \\
\hline Total & 76 & 98.7 \\
\hline \multicolumn{3}{|l|}{ Survival } \\
\hline Alive & 39 & 50.6 \\
\hline Death & 38 & 49.4 \\
\hline Total & 77 & 100 \\
\hline \multicolumn{3}{|l|}{ Cause of death } \\
\hline Metastasis & 26 & 68,4 \\
\hline Relapse & 7 & 18.4 \\
\hline Other cause & 5 & 13.2 \\
\hline Total & 38 & 100 \\
\hline \multicolumn{3}{|l|}{ Family history } \\
\hline Yes & 3 & 3.9 \\
\hline No & 74 & 96.1 \\
\hline Total & 77 & 100 \\
\hline
\end{tabular}

TABLE 2: Clinical characteristics of the study population

Post-surgical staging showed most patients being classified in stages-III (39\%), IV (26\%), and I (26\%), while only 7 (9.1\%) patients were classified in stage-II (Table 3). Histologically, nasopharyngeal carcinoma based on the World Health Organization (WHO) is subdivided into three categories. Our results showed that $70.1 \%$ of the volumes were WHO-III, 20.8\% WHO-II, 5.2\% WHO-I, and for three patients, no histological report was available. 


\section{Cureus}

Characteristic

Stage

I

III

IV

T: Size or direct extent of the primary tumour

$\mathrm{T} 1$

T 2

T 3

$\mathrm{T} 4$

$\mathrm{N}$ : Degree of spread to regional lymph nodes

$\mathrm{NO}$

N 1

N 2

N 3

M: Presence of distant metastasis

M 0

M 1

Tota

Histological type

WHO-I

WHO-II

WHO-III

Total n

20

7

30

20

61

10

2

4

22

8

31

16

76

1

77

4

16

54

74
$\%$

26

9.1

39

26

79.2

13

2.6

5.2

28.6

10.4

40.3

20.8

98,7

1,3

100

5.2

20.8

70.1

96.1

TABLE 3: Staging and histological characteristics of the study population

\section{Survival analysis results}

Five-Year and 10-year survival of the 77 patients with NPC were estimated by Kaplan-Meier analysis. The overall 5- and 10-year survival of NPC patients was $58.8 \%$ and $43.6 \%$, respectively (Figure 1 ). 


\section{Cureus}

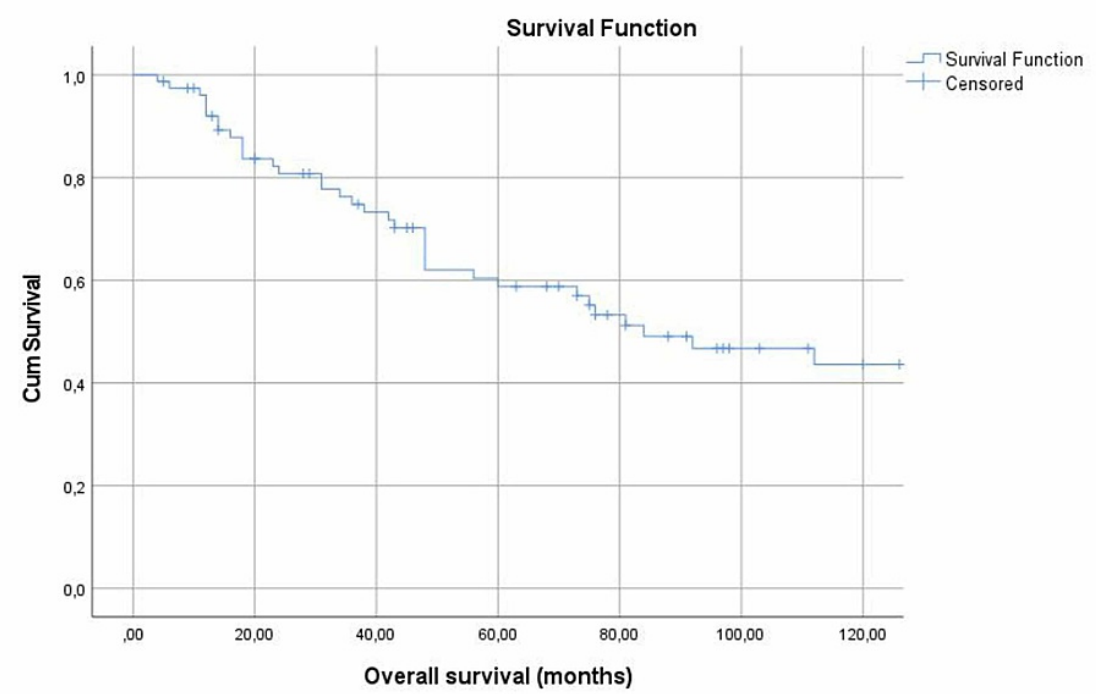

FIGURE 1: Five-year and 10-year survival of the study population

Based on gender, the results showed that the 5-year survival rate for men was $56.7 \%$ and for women $68.9 \%$, whereas the 10-year survival for men (43.2\%) did not differ from that for women (43.1\%). However, no significant statistical differences were observed between genders $(\mathrm{p}=0.620)$ (Table 4$)$.

\begin{tabular}{|c|c|c|c|}
\hline \multirow[t]{2}{*}{ Prognostic factors } & \multicolumn{3}{|c|}{ Overall survival } \\
\hline & 5 year (\%) & 10 year (\%) & $\mathrm{p}$-value \\
\hline \multicolumn{4}{|l|}{ Gender ( $\mathrm{n}=77)$} \\
\hline Male $(n=62)$ & $56.7 \%$ & $43.2 \%$ & \multirow{2}{*}{0.620} \\
\hline Female $(n=15)$ & $68.9 \%$ & $43.1 \%$ & \\
\hline \multicolumn{4}{|l|}{ Age grup $(n=77)$} \\
\hline$<30(n=5)$ & $100 \%$ & $100 \%$ & \multirow{4}{*}{0.054} \\
\hline $30-50(n=22)$ & $76 \%$ & $60.8 \%$ & \\
\hline $51 \varepsilon \dot{\varepsilon} \omega{ }_{5} 70(n=38)$ & $49.8 \%$ & $34.9 \%$ & \\
\hline$>70(n=12)$ & $45.5 \%$ & $27.3 \%$ & \\
\hline \multicolumn{4}{|l|}{ Stage (TNM) $(\mathrm{n}=77)$} \\
\hline Stage-I $(n=20)$ & $73.2 \%$ & $43.9 \%$ & \multirow{4}{*}{0.179} \\
\hline Stage-II (n=7) & $71.4 \%$ & $47.6 \%$ & \\
\hline Stage-III $(n=30)$ & $40.3 \%$ & $26.8 \%$ & \\
\hline Stage-IV (n=20) & $76.5 \%$ & $66.9 \%$ & \\
\hline \multicolumn{4}{|c|}{ Metastasis (TNM) $(\mathrm{n}=77)$} \\
\hline M0 (n=76) & $59.6 \%$ & $44.2 \%$ & \multirow{2}{*}{0.007} \\
\hline M1 $(n=1)$ & $0 \%$ & & \\
\hline \multicolumn{4}{|l|}{ Smokers $(n=76)$} \\
\hline Yes $(n=50)$ & $49.1 \%$ & $31.6 \%$ & \multirow{2}{*}{0.016} \\
\hline No $(n=26)$ & $74.5 \%$ & $63.4 \%$ & \\
\hline \multicolumn{4}{|c|}{ Histological type $(n=74)$} \\
\hline WHO-I (n=4) & $33.3 \%$ & $33.3 \%$ & \\
\hline
\end{tabular}




\section{Cureus}

\begin{tabular}{|c|c|c|c|}
\hline WHO-II (n=16) & $56.3 \%$ & $35.7 \%$ & \multirow[t]{2}{*}{0.945} \\
\hline WHO-III (n=54) & $58.8 \%$ & $47.5 \%$ & \\
\hline \multicolumn{4}{|l|}{ Treatment period $(n=76)$} \\
\hline Radio-Chemotherapy $(n=66)$ & $64.1 \%$ & $46.1 \%$ & \multirow{2}{*}{0.53} \\
\hline Radiotherapy (n=10) & $23.3 \%$ & $23.3 \%$ & \\
\hline \multicolumn{4}{|l|}{ Surgical treatment $(n=76)$} \\
\hline Yes $(n=16)$ & $58.2 \%$ & $23.3 \%$ & \multirow{2}{*}{0.673} \\
\hline No $(n=60)$ & $58.5 \%$ & $47.8 \%$ & \\
\hline \multicolumn{4}{|l|}{ Cause of death } \\
\hline Metastasis & $32 \%$ & $12 \%$ & \multirow{3}{*}{0.033} \\
\hline Relapse & $0 \%$ & & \\
\hline Another cause & $50 \%$ & $0 \%$ & \\
\hline \multicolumn{4}{|l|}{ Treatment period $(n=76)$} \\
\hline 1990-1996 & $14.3 \%$ & -- & \multirow{4}{*}{0.002} \\
\hline 1997-2003 & $30.8 \%$ & $15.4 \%$ & \\
\hline 2004-2010 & $70 \%$ & $53.8 \%$ & \\
\hline 2011-2017 & $92.3 \%$ & $(---)$ & \\
\hline
\end{tabular}

TABLE 4: Five-year and 10-year overall survival of patients with nasopharyngeal carcinoma according to various demographic and clinical characteristics. P-value between prognostic factors.

Subsequently, the patients were categorized based on their age $(\mathrm{p}=0.054)$. Specifically, in patients younger than 30 years, both, the 5 -year and 10 -year survival was $100 \%$, while among those aged 30 -50 years, the survival reached $76 \%$ and $60.8 \%$, respectively. For patients aged 51 to 70 years, 5 - and 10 -year survival was $49.8 \%$ and $34.9 \%$ respectively, whereas in patients over 70 years old, the 5 - and 10 -year survival was calculated at $45.5 \%$ and $27.3 \%$, respectively (Figure 2).

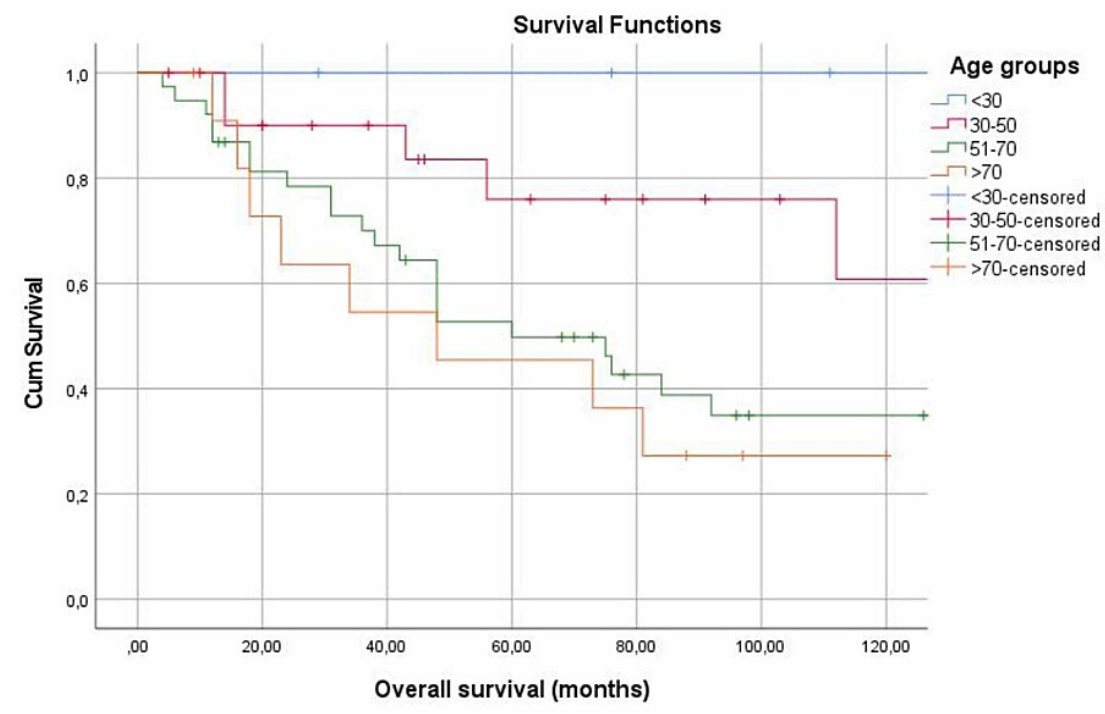

FIGURE 2: 5-year and 10-year survival of age groups 
Based on Metastases (M), Kaplan-Meier analysis results showed that patients with the nonmetastatic disease (M0) had a 5-year survival of 59\% and 10 -year survival of $45.2 \%$. In contrast, when the tumor has spread to areas of the body away from the nasopharynx (M1), 5-year survival was $0 \%(\mathrm{p}=0.007)$ (Table 4).

The staging of nasopharyngeal carcinoma was based on the TNM Staging System. For stage-I, the 5-year survival rate was $73.2 \%$, whereas the 10 -year survival was $43.9 \%$, for stage-II, $71.4 \%$ and $47.6 \%$, and for stage-III, $40.3 \%$ and $26.8 \%$, respectively. However, for stage-IV, the 5 -year survival rate was $76.5 \%$, and after 10 years, it was still $66.9 \%$ (Table 4 ).

Histologically and based on the World Health Organization ( $\mathrm{p}=0.945)$, Kaplan-Meier analysis showed that in squamous cell carcinoma (WHO type I) both 5-year and 10-year survival rates were 33.3\%. In non-coronary squamous cell carcinoma (WHO type II), the 5-year survival was 56.3\% and 10 -year survival $35.7 \%$.

Moreover, unlike the two previous types, in undifferentiated carcinoma/lymphoepithelioma (WHO type III), 5 -year survival was $58.8 \%$, whereas 10 years later, $47.5 \%$ of the patients were still alive (Table 4 ).

Because of the anatomical location of NPC and its tendency for rapid bilateral spread to the cervical lymph nodes, the selected treatment is mainly radiotherapy alone or in combination with chemotherapy. Patients undergoing chemotherapy and radiotherapy were analyzed during the course of the disease, and their 5- and 10 -year survival rates were $64.1 \%$ and $46.1 \%$, respectively. In contrast, patients who receive only radiotherapy ( $\mathrm{p}=0.05$ ) had a 5-year and 10 -year survival of $23.3 \%$ (Figure 3). Furthermore, the 5- and 10-year survival of patients undergoing surgery was $58.2 \%$ and $23.3 \%$, whereas in patients who did not enter surgery ( $\mathrm{p}=0.673$ ), the rate was $58.5 \%$ and $47.8 \%$, respectively (Table 4 ).

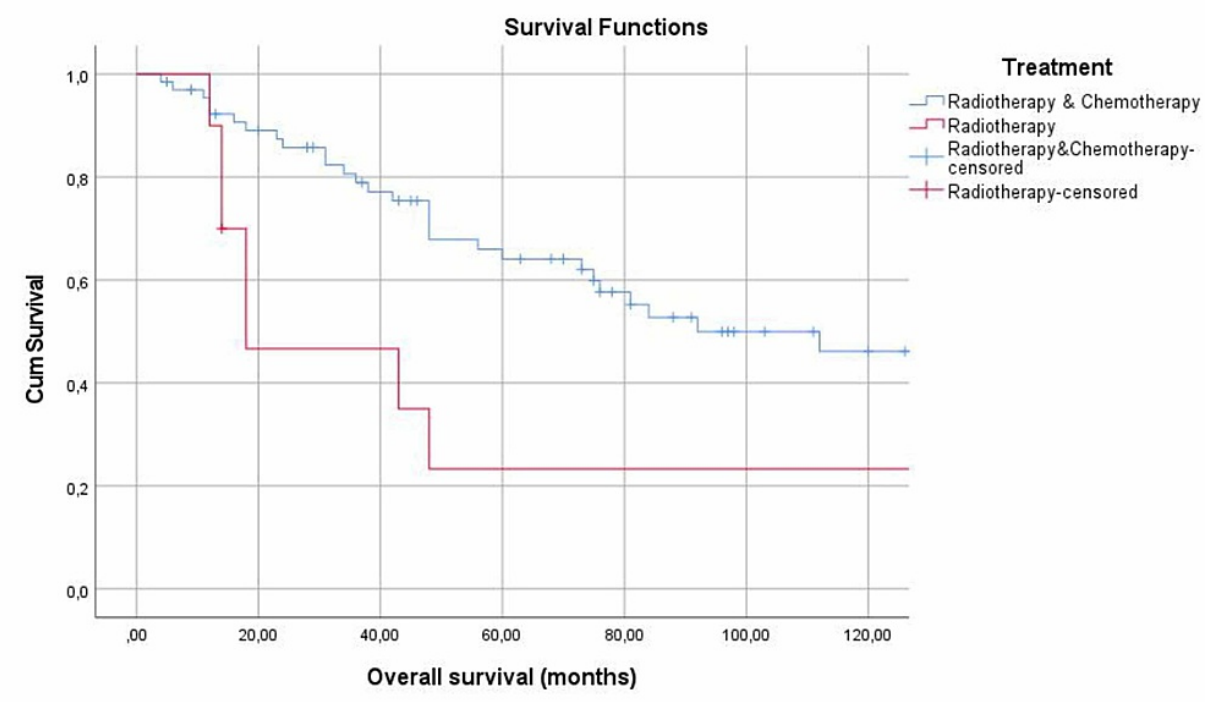

FIGURE 3: 5- and 10-year survival in association to treatment

Smoking is one of the main risk factors for NPC and especially long-lasting (20 or more cigarettes a day). Statistical analysis showed that smokers had lower survival rates than non-smokers $(\mathrm{p}=0.016)$. Specifically, $49.1 \%$ of smokers were alive after 5 -years and $31.6 \%$ after 10-years, whereas non-smokers showed higher survival rates of $74.5 \%$ and $63.4 \%$, respectively (Figure 4 ). 


\section{Cureus}

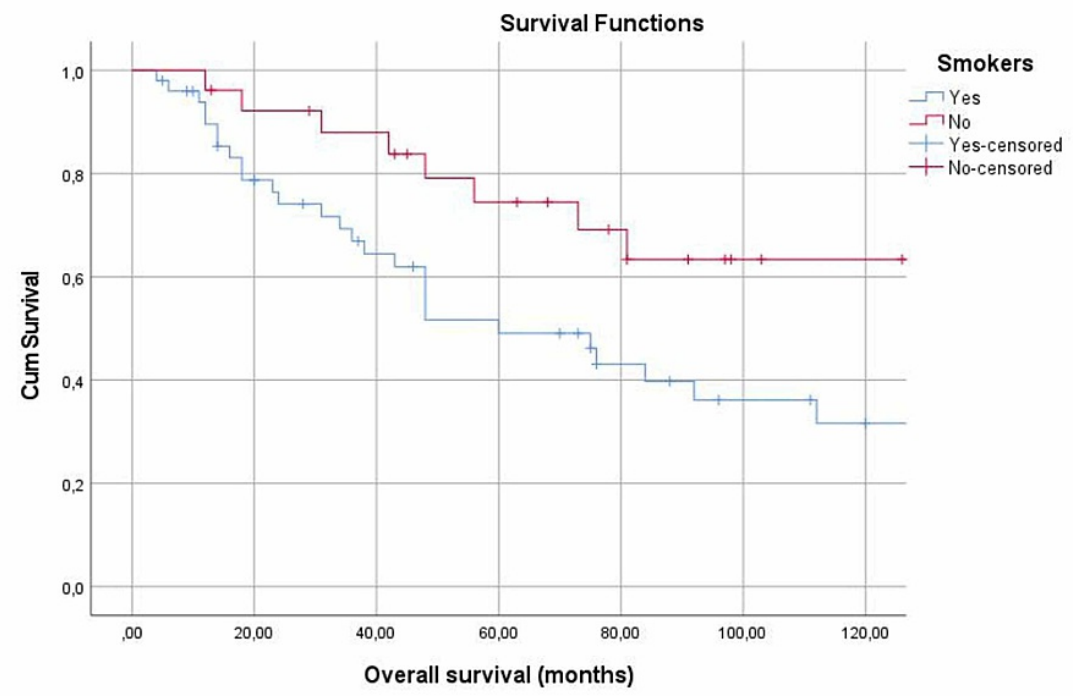

FIGURE 4: 5- and 10-year survival in association to smoking habits

Based on the cause of death $(\mathrm{p}=0.033)$, patients with metastatic or generalized carcinomatosis showed a 5and 10 -year survival rate of $32 \%$ and $12 \%$ and none of the relapsed patients was still alive after 5 -years. In contrast with this, patients who died from other causes, unrelated to the disease, had a $50 \%$ survival rate after 5 -years, but none of them survived 10-years after the diagnosis (Table 4).

Last but not least, we examined the survival relating to the time period when the diagnosis and treatment was done ( $\mathrm{p}=0.002$ ) (Table 4). Patients diagnosed and treated during the period 1990-1996 had the lowest 5and 10-year survival rates (14.3\% and $0 \%$ ), while in the last period 2011-2017, we observed a 5-year survival rate of $92.3 \%$ (Figure 5).

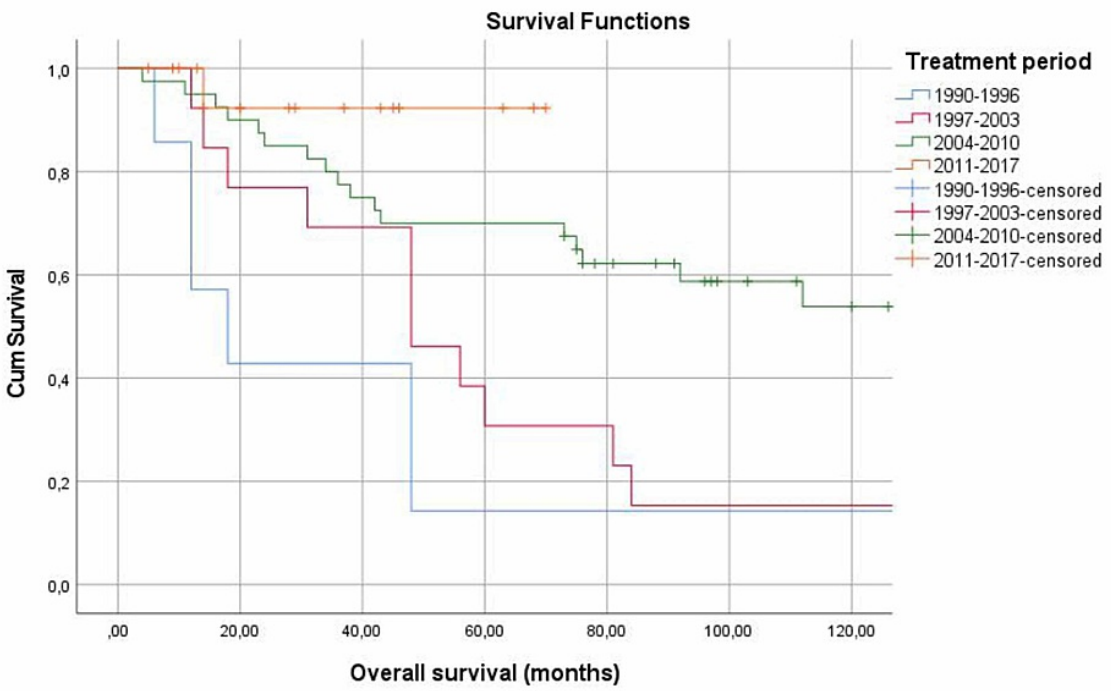

FIGURE 5: 5- and 10-year survival in association to time period of diagnosis and treatment

\section{Discussion}

Nasopharyngeal carcinoma (NPC) is the most common cancer originating from the nasopharynx, which occupies a separate geographical and tribal distribution [7]. The incidence of nasopharyngeal cancer in men is two to three times higher than in women [8]. Our study showed a higher incidence of diagnosis and cancer deaths in males, which is also shown in other studies [9]. Differences between men and women may be due to different lifestyle habits or biological indices $[9,10]$. 
In addition, in most low-risk groups, the incidence of NPC is stable with age increase [11,12]. We observed statistically higher 5-year and 10-year survival rates in younger age groups compared to older age groups. Our findings are similar to those of other researchers [13], where a decrease in survival rates with age is reported. According to studies, this may be due to the fact that elderly patients at the time of diagnosis may die as a result of treatment complications, as they may be unable to tolerate the aggressiveness of the therapeutic approach [13].

Another factor studied was smoking, which is the most important risk factor for head and neck cancer. Over time, many studies $[14,15]$ have highlighted that smoking is directly related to nasopharyngeal cancer and especially long-term heavy smoking [16]. In our study, over $50 \%$ of the incidents were active smokers. Statistical analysis showed that smokers had lower survival rates than non-smokers. The study by Rodriguez and Adelstein reports a negative impact on the survival of patients who continue to smoke after treatment, suggesting that smoking cessation can improve survival [17]. Also, according to Galbiatti et al. [18], there is a significant reduction in the risk of developing the disease when the patient stops smoking.

Currently, the mapping and prognosis of NPC patients are assessed primarily using the TNM Staging System. The clinical stage at diagnosis is an independent survival factor in both 5 and 10 years of follow-up. According to studies, the 5-year survival rate of patients with stage-I NPC was 90\% or more [19]. Treatment of intermediate stage-II NPC results in 5-year survival and relapse-free survival of $77 \%$ and $62 \%$, respectively, while about $30 \%$ of patients relapse with metastatic disease [20]. For stage-III and IV, the prognosis is poorer and relapse with distant metastases is common [21].

Lack of awareness continues to be a major barrier to the management of NPC in our area, which is added to delayed presentation to health services (64\% of the cases were stage-III and IV). Regarding the survival analysis, we found higher survival rates in patients of stage-IV. Most of these patients were non-smokers, young, and received radiotherapy and chemotherapy. In contrast, literature data showing higher mortality rates in advanced stage-III and IV [22]. It is noteworthy that in some cases, there are differences between TNM stages and clinical outcomes [23]. Patients in the same staging class showed different survival effects due to the inability of the TNM system to reflect the biological heterogeneity between the tumors [7].

Nasopharyngeal carcinoma is traditionally treated with radical radiotherapy and with or without chemotherapy due to the radiosensitivity of the neoplasm and the difficulty in surgical access to it due to anatomical constraints $[13,24]$. In our study, almost all patients received radiotherapy with the exception of five cases that followed another treatment regimen. Moreover, NPC is a chemosensitive neoplasm, with rates of $60-74 \%$ responses to first-line chemotherapy [20]. According to bibliographic reports, no survival benefit from radiotherapy has been demonstrated, followed by adjuvant chemotherapy against radiotherapy alone, or by induction chemotherapy [25].

However, as shown in meta-analyses, the benefit of adding chemotherapy was mainly due to simultaneous administration with radiotherapy [26]. The results of our study are consistent with the above-mentioned reports, as we observed higher survival rates in patients receiving additional chemotherapy than those receiving radiotherapy only (5-year survival rate $23.3 \%$ ).

Another important observation was the period of occurrence and treatment of the disease every seven years. We found that over time there were increased survival rates in these patients. Specifically, survival rates were found significantly higher during 2011-17 compared to 2004-10. Our findings complement other research that showed 5-year survival over the period 1971-2011 had increased for most cancers [27].

In addition, it is noteworthy to mention an epidemiological study from Taiwan showing a reduction by $30 \%$ in the age-standardized incidence rate between 1981 and 2000 [28].

The retrospective analysis of the last 28 years allowed us an insight into the survival rates of patients with NPC in Western Greece. Comparing the results of our study with those of other countries, no significant differences in survival rates are observed between Western Greece and European countries or the US [29-30], while large variations in the values of each parameter are seen in Malaysia, Singapore, Indonesia, Southeast Asia, Kenya in Northern Africa, and Southern China according to international literature [30].

However, the limitations should be taken into account when interpreting these results. First, retrospective analysis may inherently bias the study. Second, the relatively rare disease and the limited availability of complete records of the studied patients. Third, factors such as patients' blood groups, previous Epstein-Barr infection not studied. Finally, this study represents approximately $6.3 \%$ of the population of Greece.

\section{Conclusions}

In conclusion, it is worth noting that a) a higher number of male than female patients were treated in the hospital, b) It is a rare form of cancer in Western Greece, c) Elderly patients in relation to younger age groups have a higher risk of relapse and lower overall survival, d) smoking seems to affect the 5-year and 10-year survival of these patients, e) 5-year and 10-year survival rates are influenced by age, diagnosis, and 
treatment choice, and f) the differences recorded in survival rates during the last two decades support that improvements in treatment and the introduction of the combined chemotherapy and radiotherapy have improved survival rates.

\section{Additional Information \\ Disclosures}

Human subjects: Consent was obtained or waived by all participants in this study. Animal subjects: All authors have confirmed that this study did not involve animal subjects or tissue. Conflicts of interest: In compliance with the ICMJE uniform disclosure form, all authors declare the following: Payment/services info: All authors have declared that no financial support was received from any organization for the submitted work. Financial relationships: All authors have declared that they have no financial relationships at present or within the previous three years with any organizations that might have an interest in the submitted work. Other relationships: All authors have declared that there are no other relationships or activities that could appear to have influenced the submitted work.

\section{Acknowledgements}

As a sign of love and gratitude, we would like to dedicate this article to an outstanding person and scientist, Professor of Otolaryngology, Papadas Theodoros, who on 2/4/2019, at age 64, passed away unexpectedly from us, filling affliction and sadness to all of us, who had the chance to get to know him. So if we accept as a result of the pain caused by his sudden loss, the essential feelings that he inspired us with his life course, the brilliant scientist, the enviable family, the man of offering and selflessness, the trusted friend and honest servant of medical science, there can only be one promise: That for his family, students, friends, patients, and for the medical community, he will stay as a special man and scientist with ethos and humanity. Himself and the examples given by him will always remain alive in our memories.

\section{References}

1. Bray F, Ferlay J, Soerjomataram I, Siegel RL, Torre LA, Jemal A: Global cancer statistics 2018: GLOBOCAN estimates of incidence and mortality worldwide for 36 cancers in 185 countries. CA Cancer J Clin. 2018, 68:394-42. 10.3322/caac.21492

2. Haleshappa RA, Thanky AH, Kuntegowdanahalli L, Kanakasetty GB, Dasappa L, Jacob L: Epidemiology and outcomes of nasopharyngeal carcinoma: experience from a regional cancer center in Southern India. South Asian J Cancer. 2017, 6:122-4. 10.4103/2278-330X.214578

3. Tian YM, Xiao WW, Bai L, Liu XW, Zhao C, Lu TX, Han F: Impact of primary tumor volume and location on the prognosis of patients with locally recurrent nasopharyngeal carcinoma. Chin J Cancer. 2015, 34:247-53. 10.1186/s40880-015-0019-5

4. Zhang L, Zhu YX, Wang Y, Huang CP, Wu Y, Ji QH: Salvage surgery for neck residue or recurrence of nasopharyngeal carcinoma: a 10-year experience. Ann Surg Oncol. 2011, 18:233-8. 10.1245/s10434-0101292-9

5. Zhang MX, Li J, Shen GP, et al.: Intensity-modulated radiotherapy prolongs the survival of patients with nasopharyngeal carcinoma compared with conventional two-dimensional radiotherapy: a 10-year experience with a large cohort and long follow-up. Eur J Cancer. 2015, 51:2587-95. 10.1016/j.ejca.2015.08.006

6. Chua ML, Wee JT, Hui EP, et al.: Nasopharyngeal carcinoma. Lancet. 2016, 387:1012-24. 10.1016/S01406736(15)00055-0

7. Su WH, Chiu CC, Yao Shugart Y: Heterogeneity revealed through meta-analysis might link geographical differences with nasopharyngeal carcinoma incidence in Han Chinese populations. BMC Cancer. 2015, 15:598. 10.1186/s12885-015-1607-0

8. Parkin DM, Whelan SL, Ferlay J, Teppo L, Thomas DB: Cancer Incidence in Five Continents Volume VIII: IARC Scientific Publication No. 155. IARC Publications, Lyon; 2002.

9. Attar E, Dey S, Hablas A, Seifeldin IA, Ramadan M, Rozek LS, Soliman AS: Head and neck cancer in a developing country: a population-based perspective across 8 years. Oral Oncol. 2010, 46:591-6. 10.1016/j.oraloncology.2010.05.002

10. Jia WH, Qin HD: Non-viral environmental risk factors for nasopharyngeal carcinoma: a systematic review . Semin Cancer Biol. 2012, 22:117-26. 10.1016/j.semcancer.2012.01.009

11. Sun LM, Epplein M, Li CI, Vaughan TL, Weiss NS: Trends in the incidence rates of nasopharyngeal carcinoma among Chinese Americans living in Los Angeles County and the San Francisco metropolitan area, 1992-2002. Am J Epidemiol. 2005, 162:1174-8. 10.1093/aje/kwi345

12. Luo J, Chia KS, Chia SE, Reilly M, Tan CS, Ye W: Secular trends of nasopharyngeal carcinoma incidence in Singapore, Hong Kong and Los Angeles Chinese populations, 1973-1997. Eur J Epidemiol. 2007, 22:513-21. 10.1007/s10654-007-9148-8

13. Pulte D, Brenner $\mathrm{H}$ : Changes in survival in head and neck cancers in the late 20th and early 21st century: a period analysis. Oncologist. 2010, 15:994-1001. 10.1634/theoncologist.2009-0289

14. Ekburanawat W, Ekpanyaskul C, Brennan P, et al.: Evaluation of non-viral risk factors for nasopharyngeal carcinoma in Thailand: results from a case-control study. Asian Pac J Cancer Prev. 2010, 11:929-32.

15. Nesić V, Sipetić S, Vlajinac H, Stosić-Divjak S, Jesić S: Risk factors for the occurrence of undifferentiated carcinoma of nasopharyngeal type: a case-control study. Srp Arh Celok Lek. 2010, 138:6-10. 10.2298/sarh1002006n

16. Hashibe M, Brennan P, Benhamou S, et al.: Alcohol drinking in never users of tobacco, cigarette smoking in never drinkers, and the risk of head and neck cancer: pooled analysis in the International Head and Neck 
Cancer Epidemiology Consortium. J Natl Cancer Inst. 2007, 99:777-89. 10.1093/jnci/djk179

17. Rodriguez CP, Adelstein DJ: Survival trends in head and neck cancer: opportunities for improving outcomes . Oncologist. 2010, 15:921-3. 10.1634/theoncologist.2010-0237

18. Galbiatti AL, Padovani-Junior JA, Maníglia JV, Rodrigues CD, Pavarino ÉC, Goloni-Bertollo EM: Head and neck cancer: causes, prevention and treatment. Braz J Otorhinolaryngol. 2013, 79:239-47. 10.5935/18088694.20130041

19. Chua DT, Sham JS, Kwong DL, Au GK: Treatment outcome after radiotherapy alone for patients with stage III nasopharyngeal carcinoma. Cancer. 2003, 98:74-80. 10.1002/cncr.11485

20. Jin Y, Cai XY, Shi YX, et al.: Comparison of five cisplatin-based regimens frequently used as the first-line protocols in metastatic nasopharyngeal carcinoma. J Cancer Res Clin Oncol. 2012, 138:1717-25. 10.1007/s00432-012-1219-X

21. Liu Z, Fang F, Chang ET, Ye W: Cancer risk in the relatives of patients with nasopharyngeal carcinoma-a register-based cohort study in Sweden. Br J Cancer. 2015, 112:1827-31. 10.1038/bjc.2015.140

22. Mak HW, Lee SH, Chee J, et al.: Clinical outcome among nasopharyngeal cancer patients in a multi-ethnic society in Singapore. PLoS One. 2015, 10:e0126108. 10.1371/journal.pone.0126108

23. Sun R, Qiu HZ, Mai HQ, et al.: Prognostic value and differences of the sixth and seventh editions of the UICC/AJCC staging systems in nasopharyngeal carcinoma. J Cancer Res Clin Oncol. 2013, 139:307-14. 10.1007/s00432-012-1333-9

24. Lee AW, Ma BB, Ng WT, Chan AT: Management of nasopharyngeal carcinoma: current practice and future perspective. J Clin Oncol. 2015, 33:3356-64. 10.1200/JCO.2015.60.9347

25. Chua DT, Ma J, Sham JS, et al.: Long-term survival after cisplatin-based induction chemotherapy and radiotherapy for nasopharyngeal carcinoma: a pooled data analysis of two phase III trials. J Clin Oncol. 2005, 23:1118-24. 10.1200/JCO.2005.12.081

26. Baujat B, Audry H, Bourhis J, et al.: Chemotherapy in locally advanced nasopharyngeal carcinoma: an individual patient data meta-analysis of eight randomized trials and 1753 patients. Int J Radiat Oncol Biol Phys. 2006, 64:47-56. 10.1016/j.ijrobp.2005.06.037

27. Quaresma M, Coleman MP, Rachet B: 40-year trends in an index of survival for all cancers combined and survival adjusted for age and sex for each cancer in England and wales, 1971-2011: a population-based study. Lancet. 2015, 385:1206-18. 10.1016/S0140-6736(14)61396-9

28. Hsu C, Shen YC, Cheng CC, Hong RL, Chang CJ, Cheng AL: Difference in the incidence trend of nasopharyngeal and oropharyngeal carcinomas in Taiwan: implication from age-period-cohort analysis. Cancer Epidemiol Biomarkers Prev. 2006, 15:856-61. 10.1158/1055-9965.EPI-05-0821

29. Chang ET, Adami HO: The enigmatic epidemiology of nasopharyngeal carcinoma . Cancer Epidemiol Biomarkers Prev. 2006, 15:1765-77. 10.1158/1055-9965.EPI-06-0353

30. Tang LL, Chen WQ, Xue WQ, He YQ, Zheng RS, Zeng YX, Jia WH: Global trends in incidence and mortality of nasopharyngeal carcinoma. Cancer Lett. 2016, 374:22-30. 10.1016/j.canlet.2016.01.040 